\title{
The Cognitive Appeal of the Cosmological Argument*
}

\author{
Johan De Smedt \\ Department of Philosophy and Ethics, Universiteit Gent, Gent, Belgium \\ johan.desmedt@ugent.be \\ Helen De Cruz \\ Centre for Logic \& Philosophy of Science, Katholieke Universiteit Leuven, Leuven, Belgium \\ helen.decruz@hiw.kuleuven.be
}

\begin{abstract}
The cosmological argument has enjoyed and still enjoys substantial popularity in various traditions of natural theology. We propose that its enduring appeal is due at least in part to its concurrence with human cognitive predispositions, in particular intuitions about causality and agency. These intuitions seem to be a stable part of human cognition. We will consider implications for the justification of the cosmological argument from externalist and internalist perspectives.
\end{abstract}

\section{Keywords}

cosmological argument, natural theology, causal cognition, agency detection, developmental psychology, reformed epistemology, epistemic satisfaction

The cosmological argument infers the existence of God from the existence of the universe. It has been developed in various forms of Christian, Jewish and Islamic theology since the Middle Ages. Early examples include the Kalām cosmological argument, formulated by amongst others Ibn Rushd (Averroes) and al-Ghazālī, the second and third of Thomas Aquinas' "five ways," Duns Scotus' argument from contingency, and cosmological arguments based on the principle of sufficient reason by Leibniz and Clarke. Despite an equally distinguished list of critics (e.g., Hume, Kant, Russell, Broad), it still enjoys a

* This study was supported by a grant provided by the Cognition, Religion and Theology Project at the University of Oxford, funded by the John Templeton Foundation and grant COM07/PWM/001 from Ghent University. The views expressed here are not necessarily those of the funding institutions. We wish to express our gratitude to Kelly James Clark, Peter Byrne, Matthew Day, and the anonymous reviewers for their suggestions to an earlier version of this paper, as well as to the audience in the European Conference on Science and Theology at Edinburgh University (April 7-11, 2010) for their helpful comments. 
widespread popularity in contemporary philosophy of religion (e.g., Craig 2003, Koons 1997, Swinburne 2004).

This paper does not provide an analysis of the formal properties of the cosmological argument, but rather, focuses on the intuitions that lie at its basis. We propose that the enduring appeal of the cosmological argument is due at least in part to its concurrence with human cognitive predispositions-in particular intuitions about causality and agency. We argue that intuitions about causality underlie the inference of an external cause of the universe, whereas predispositions towards agency make God a natural candidate for this cause. Even modern versions of the cosmological argument that are couched in sophisticated modal terms are based on, and ultimately stand or fall with, the soundness of these intuitions. The link between the cosmological argument and the structure of human reasoning was first proposed by Kant (1781 [2005]), who claimed that arguments from natural theology are unavoidable given the structure of human reason. For Kant, the intuitions that underlie the cosmological argument (such as our propensity to look for explanations or to seek necessary causes) are regulative ideas of human reason, which bring 'systematic unity into our cognition' (Kant 1781[2005], A616/B644). The crucial difference between his and the present account is that Kant could only rely on introspection when considering causal intuition, whereas present philosophers can also draw on empirical data from cognitive science.

We also examine the implications of cognitive science for the cogency of cosmological arguments. In particular, we explore an externalist argument that is based on evolutionary considerations: our natural capacities for causal inference have evolved in response to selective problems related to everyday experience. However, this may cast doubt on their reliability in the domain of metaphysical inquiry. A second externalist line of reasoning is based on Reformed epistemology: cognitive science shows that our beliefs about causality and agency are properly basic, and therefore at least prima facie justified. The final section examines an internalist approach where cosmological arguments fulfill an epistemic need. Answering the question of why there is a universe by positing an agent may afford an epistemic sense of satisfaction, provided that one already accords a high prior probability to the existence of God. In this way, the cosmological argument can contribute to a coherent worldview for theists.

Before proceeding, a caveat is in order. The central issues of this paper are on the one hand a meta-causal question (i.e., what are the causes for our causal reasoning?) and on the other hand a question of justification (i.e., how do causal intuitions figure in the justification of the cosmological argument?). A familiar philosophical metaphor to distinguish between these two questions is 
the Sellarsian dichotomy between the Space of Reasons and the Space of Causes (e.g., Sellars, 1956). The cosmological argument as formulated by theologians and philosophers of religion is situated in the space of reasons and justification: it is motivated by propositions (reasons or candidate reasons) that present themselves to our judgment and that guide our inferences. These reasons cannot be reduced to the fact that cosmological arguments are appealing - after all, as Davidson (1963) observed, there are many things that may hold a certain appeal but to which we would be unwilling to subscribe. What can be a compelling reason for accepting the cosmological argument is that it concurs with basic human intuitions about causality and agency. The cognitive origins of these intuitions can be located in a space of lawlike processes, such as regularities in cognitive development. When examining the cognitive origin of intuitions that underlie the cosmological argument, we are in effect proposing a causal factor that impinges upon the space of reasonssuch a factor would not strictly speaking be a move within the space of reasons and therefore, according to Sellars (1956), would lack justification.

Nonetheless, from a methodologically naturalistic point of view, there is no unbridgeable gap between causes and reasons, but a fundamental continuity in the causal natural order: human minds and the thoughts they form do not stand outside this natural order (Blackburn 2001). Consequently, naturalists have attempted to bridge the gap between causes and reasons. For example, Hurley (2003) has argued that animals can make flexible decisions within specific contexts that are driven by cognitive adaptations (e.g., in their social interactions with conspecifics). According to this line of thought (cf. Hurley 2003), we can say of these animals that they have reasons for their actions, even though these reasons are never made explicit (by the animals themselves), and even though these reasoning processes only work under quite specific, ecologically relevant conditions. McDowell (1996) has developed the classic notion of Bildung (upbringing and education) to account for our ability to make ethical or normative judgments. To McDowell (1996), these habits would be sufficient to constitute an individual's competence in the space of reasons.

However, Bildung naturalism still requires an account of how these habits, which together constitute our rational capacity, are acquired. Unfortunately, such an account has not been outlined yet. Pollard (2005) has suggested that developmental psychology might help us in this endeavor. A considerable part of the empirical and theoretical psychological work on which this paper is based comes from developmental psychology. Developmental psychologists (e.g., Spelke \& Kinzler, 2007) have proposed that humans are equipped with a set of core principles that regulate their knowledge acquisition, amongst 
others in the domains of physics and agency. These principles are phylogenetically old, emerge early in development, and remain stable throughout adult life; they are elaborated and enriched through experience and education, but not fundamentally revised (Carey \& Spelke, 1996). As we shall argue, intuitions about causality and agency which are present in young children are still regulative in the formulation of the cosmological argument. In other words, the habits that underlie our reasoning about causation are partly based on early-developed intuitions that are enriched but not overturned through experience or education. If developmental psychologists are correct in proposing that core knowledge still 'guides and shapes the mental lives of adults' (Spelke \& Kinzler, 2007, 89), these intuitions can continue to play a role in shaping the reasoning that guides human inferences, including those in philosophical and theological reflection. Thus, our examination of origins of the intuitions that underlie the cosmological argument can be seen within a methodological naturalistic framework that seeks to relate causes and reasons.

\section{Causal Cognition and the Cosmological Argument}

Most cosmological arguments proceed in two steps: first, they establish that the existence of the universe must have a cause, and second, they identify this cause with God. ${ }^{1}$ In this first step, historical versions of the cosmological argument (e.g., the Kalām and Thomistic versions) rely on the causal principle: every contingent state of affairs has a cause of its existence. This is also the case for contemporary versions of the cosmological argument, although they attempt to replace intuitions with more rigorous logical argumentation. For example, Rasmussen (2010) provides an updated version of Duns Scotus' argument from contingency: necessarily, for all contingent concrete objects or their duplicates, it is possible that they have a causal origin. More formally presented:

(Normally, $\forall S((S$ is a contingent state of existence) $\diamond$ (S’s obtaining, or the obtaining of a duplicate of $S$, is causally explained))).

Using this causal principle, Rasmussen (2010) derives the existence of a necessary being wielding $S 5$ modal logic. To justify the causal principle, however, he draws upon his causal intuitions in everyday experience of objects:

\footnotetext{
${ }^{1}$ In the discussion of the causal principle, this paper will leave aside inductive versions of the cosmological argument, such as Swinburne (2004).
} 
Consider, for example, your favorite armchair. Surely the armchair's existence can be the result of causal factors, such as a craftsman or factory machine piecing together materials. (Indeed, it certainly was.) [...] The principle seems to apply to very small objects, too: neutrinos, for example, can be produced from proton collisions in a particle accelerator. It's natural to generalize: necessarily, any contingent concrete object can have a cause (Rasmussen, 2010, 185, emphasis added).

Humans habitually generalize from their intuitions about causes in everyday objects to causes about any contingent concrete object. To proponents of the cosmological argument, the causal principle is a self-evident principle that hardly requires justification. Craig $(2003,117)$, for example, argues that it 'seems obviously true — at least more so than its negation.' However, critics of the cosmological argument have called this "obviousness" into question. Kant (1781[2005], A609/B637) contended that '... the principle of causality has no significance at all and no mark of its use except in the world of sense; here [in the cosmological argument], however, it is supposed to serve precisely to get beyond the world of sense.' Although we perceive the world in terms of causes, we cannot be sure that causes exist in the observer-independent world. At best, one can justify the causal principle by induction, for example, by arguing that it is constantly being confirmed in our experience, and that it holds a central place in modern scientific practice and in contemporary analytic philosophy (Koons, 1997). For Hume (1779, IX, 167), an explanation of the world in causal terms may be epistemically satisfying, but such an explanation is only 'an arbitrary act of the mind.' By this, Hume (1748, section 4, part 1) meant that the causal principle is not metaphysically necessary, but rather, that it results from a psychological disposition, where cause and effect are joined in the imagination of the observer through repeated experience. Although Hume's ideas on causal cognition are no longer followed in cognitive science, his assertion that causal reasoning has a psychological originand that such causal reasoning lies at the basis of the cosmological argument-remains sound. As will be shown in more detail below, our causal intuitions in everyday domains closely match those employed by the cosmological argument.

From an early age, humans seek causal explanations in nearly every sphere of their lives. We have an intuitive feel for whether or not an explanation is satisfying. Satisfying explanations are often those that invoke generative causes (Ahn et al., 1995). To put it a different way, our intuitive understanding of causation is not only in terms of events that covary or that are contiguous, but is also in terms of causes that can be plausibly thought to generate their effects (Shultz 1982a). People tend to infer causes spontaneously, without conscious deliberation and in the absence of instructions to do so (Hassin et al. 2002). To explain states of affairs, we frequently invoke unobservable causes such as 
internal mental states (e.g., mental fatigue) or invisible forces (e.g., gravity). This preference for unobservable, nonobvious causes is already present in young children. Preschoolers invoke unobservable mental states to explain the behavior of agents: they spontaneously attribute beliefs, desires and intentions to them, and realize that mental states can differ from the actual state of the world (Callaghan et al., 2005). Young children posit unobservable physical forces and properties to account for the motion of inanimate objects. They have, for instance, the intuition that unsupported objects fall downward due to gravity, and that one object can set another in motion when in direct contact (Shultz, 1982b). From about three years of age, children posit invisible biological properties to account for the growth and behavior of biological organisms. Such hidden properties are invoked to explain why apple seeds, planted in a flower pot, will still grow out to be apple trees, or why caterpillars turn into butterflies (Gelman \& Wellman, 1991). In sum, humans typically posit a variety of unobservable causes in many domains of reasoning.

Pace Hume, adults as well as young children tend to interpret physical causation in terms of mechanistic causes rather than simple co-occurrences, even if both types of clue (mechanism and temporal covariation) are equally available to them (Shultz, 1982a). That is, they believe that causes actually generate or produce their effects. Indeed, adults find causal explanations that invoke a plausible mechanistic causal link more convincing than those that are only closely associated in space and time (Ahn et al., 1995).

The ability to figure out causes has also been demonstrated in nonhuman animals, such as apes that can use causal cues to find the location of hidden food (Bräuer et al., 2006). Next to this, human children of four years and older as well as adults are able to infer causes of events that they never experienced before, involving objects that they are totally unfamiliar with. In a classic series of experiments, Shultz (1982a) showed Malinese children from a horticultural society (who were unfamiliar with western technology) a variety of causal events involving flashlights and tuning forks. In these experiments, the participants were more likely to say that a tuning fork that was struck caused a box to resonate, rather than a tuning fork that was closer to the box but that was not struck. Similarly, western children and adults preferred a generative account of causality to explain why the propeller of a Crookes radiometer (an instrument for measuring electromagnetic radiation that none of the subjects had ever seen) began to spin when a flashlight was turned on. Cosmological arguments postulate a cause for the existence of the universe, a unique state of affairs that cannot be compared with other events. From a psychological point of view at least, such a view is not problematic or unintelligible, as humans spontaneously make causal inferences concerning events 
with which they had no prior experience. Such causal inferences are, to use a phrase by McDowell "habits of thought and action" that collectively constitute a "second nature" $(1996,84)$. We have a rudimentary sense of causality that allows us to infer plausible causes of unique events.

As discussed earlier, humans routinely posit unobservables as underlying causes. One set of experiments that compared the behavior of human children and adult chimpanzees indicates that preschoolers - but not chimpanzeesattempt to seek a cause for their failure to perform a task (Povinelli \& Dunphy-Lelii, 2001). In this study, the participants were taught to place an oblong L-shaped block in an upright position. When the block had been visibly tampered with, so as to make the task impossible, both preschoolers and chimpanzees examined it extensively. However, when the block showed no external signs of manipulation, only the children explored it from different angles to attempt to find a reason why the task could have failed. This apparent inability of nonhuman animals to attribute invisible causes has been demonstrated in other domains as well. Human children, from an early age onwards, routinely represent false beliefs of other agents. Apes, by contrast, fail to attribute false beliefs (Call \& Tomasello 1999). The primatologists Vonk and Povinelli (2006) propose that humans may be unique in their ability to conceptualize unobservables such as gods, ghosts, gravity, and other minds. The early emergence of this ability suggests that it may be a stable feature of human cognition. The attribution of an unobservable cause for the universe in the cosmological argument is made possible by a universal human cognitive disposition to readily infer unobservable causes.

Most proponents of the cosmological argument also argue for the necessity of a cause for the existence of the universe. This part of the cosmological argument may also be informed by cognitive predispositions. When we think about causes, we intuitively think about deterministic rather than stochastic causes. When preschoolers get the choice between an observable, stochastic cause, or an unobservable, deterministic cause they strongly prefer the deterministic cause-they are "intuitive determinists" (Schulz \& Sommerville 2006). This bias toward deterministic causal factors persists until adulthood. For example, Metz (1998) compared the ability to infer stochastic causes of physical events in kindergartners, school-age children and adults. She found that the ability to recognize stochastic causes increased with age, probably an effect of education. Nevertheless, like the children, the majority of adult participants continued to infer deterministic causes for some stochastically caused events. It seems that the causal reasoning that lies at the basis of the cosmological argument is not an arbitrary act of the mind, but rather a way of reasoning that is both obvious and intuitive to humans: we readily infer generative 
causes for events, we routinely deal with unique states of affairs, we habitually infer unobservable causal mechanisms, and we have a preference for deterministic causes.

\section{Intuitions about Agency in the Identification of God}

The second step of most cosmological arguments consists of an identification of the necessary, external cause of the universe with God. This second step is important, because, as Hume (1779, IX, 164-165) already observed, one could simply argue that the material universe is metaphysically necessary. Moreover, even if we grant that the universe has an external cause, what reason do we have to identify that cause with the God of traditional theism, i.e., an infinitely powerful, all-knowing, eternal and perfectly good being? It seems reasonable to suppose that if there is an external cause to the universe, it must be a powerful entity. This does not mean that it is a person, let alone God. To justify the identification of God, Craig (2003) proposes an argument of the following form:

1. The cause of the universe is timeless and immaterial;

2. The only entities we know of which can be timeless and immaterial are minds and abstract objects;

3. Abstract objects cannot cause something to come into existence;

4. Therefore, the cause of the universe is a mind (i.e., a person).

As Rowe (2005, 114-115) rightly observes, this argument is invalid as it stands. In order to be valid, the conclusion should be:

(4a) The only entity we know of which can be the cause of the universe is a mind.

Also in this revised form, the argument relies to an important extent on our finite, human intuitions about causality, where a person is regarded as the cause for any occurrence-in this case the universe. Craig's (2003) characterization of minds as timeless and immaterial entities is akin to folk psychology. Even young children conceive of minds as immaterial entities that survive physical death-they believe, for instance, that a young mouse eaten by an alligator will nonetheless keep on feeling sad and missing its mommy (Bering et al. 2005).

Swinburne (2004) distinguishes two kinds of causes (physical and personal), which require two types of explanation, scientific and personal. To explain the 
existence of the universe as a whole, we cannot posit physical causes since there are no physical causes expect for the universe itself and its parts. Therefore, the universe is either a brute inexplicable fact, or it is explained in personal terms. Swinburne (2004, 142-145) argues in favor of the personal explanation: he invokes a person, God, who freely chooses to create and sustain the universe. Given that the physical universe is extremely complex, whereas God is simple (in the sense of undivided, not composed of parts, etc.), Swinburne argues that the theistic explanation is more likely, as it is more parsimonious: "The need for further explanation ends when we postulate one being who is the cause of the existence of all others, and the simplest conceivable such-I urge—is God" $(2004,147)$.

The identification of God as the necessary cause of the universe can be traced back to human intuitions about agents as causes. Swinburne's distinction between physical and personal causes has parallels in the cognitive psychological literature: humans draw an intuitive distinction between events that are caused by purely physical processes and those caused by agents (Gelman \& Gottfried 1996). One of these distinctions that arise already in infancy is that agents, but not inanimate objects, are able to influence the behavior of objects from a distance (Spelke et al. 1995). Pre-verbal infants seem to appreciate that only agents can create order: they exhibit surprise (as measured by a longer looking time) when a rolling ball apparently causes a disorderly heap of blocks to become nicely stacked, but not when an unseen agent (hidden behind a screen) performs the same thing (Newman et al., 2010). This intuitive distinction between objects and agents as two types of causes is a core principle of human reasoning that persists into adulthood. Neuroimaging studies of adults indicate that the perceptions of mechanical and agent-based motions are subserved by distinct and largely non-overlapping brain areas (Martin \& Weisberg, 2003). In particular, only motions performed by intentional agents activate areas reliably involved in the attribution of mental states to others. The universe exhibits a high degree of order. Our attribution of its origin to an intentional agent is furthered by these stable intuitions about agents as causes.

Purposiveness is a decisive cue for favoring agency. When adults watch simple geometric objects moving about on a screen, they interpret those motions as agent-like and explain them by reference to internal mental states if the objects appear to move in a goal-directed manner (Scholl \& Tremoulet 2003). Experimental studies suggest that the ability to identify an agent as the cause of an event arises early in development. Twelve-month-olds witnessed a beanbag landing on a stage; subsequently an object appeared on stage that could be interpreted as the cause of this event (Saxe et al. 2005). The infants looked least long when a human hand appeared, and significantly longer when a toy 
train or toy animal was shown, indicating that they expected the hand, but not the toys, to be the cause of the event. This implies that infants assume an agent to be the cause of a contingent event. This preference for agents has been shown in other studies as well. Gelman and Gottfried (1996) showed preschoolers different kinds of objects (animals, wind-up toys, other artifacts) which, under some conditions, moved without any apparent external cause. In the case of the animals, the children mostly referred to internal, biological features. However, for the artifacts, they were much more likely to attribute the motion to a person. They expressed their surprise when they saw artifacts moving by themselves, and frequently appealed to invisible agents, e.g., 'I think another invisible person did that again' (Gelman \& Gottfried, 1996, 1980). Children appeal to agents as causes when they have to explain the origin of artifacts, and even plants, animals and natural kinds. This led Kelemen (2004) to call young children 'intuitive theists,' because they discern design and purpose in nature, regardless of whether or not they were brought up in a religious environment.

Explanations that postulate agents as causes of contingent events are intuitively appealing and epistemically satisfying. Humans have a predisposition to conclude that beliefs, desires and intentions directly cause actions. They regard them as generative causes that bring about actions (e.g., one forms the desire to lift a hand, and the hand is lifted) although the actual cognitive processes that underlie human actions are far more complicated. As Wegner (2003) observes, personal accounts do not require further causal explanations. By contrast, an infinite regress of causes does not provide epistemic satisfactioninfinite regress may be rejected out of hand in many versions of the cosmological argument because it is unintelligible from the perspective of stable causal intuitions about persons.

Although the step to an agent is intuitive, the step to a single omniscient and omnipotent creator is not. Why might proponents of the cosmological argument favor God? Are they mainly motivated by background beliefs that are specific to their culture (i.e., because theologians who have developed cosmological arguments stem from monotheistic religions)? A more cognitively interesting possibility is that all-knowing, powerful agents are more intuitively appealing than normal agents.

A large empirical literature on false belief reasoning (e.g., Callaghan et al. 2005) indicates that an explicit understanding of mental states as distinct from the state of the world emerges somewhere between four and five years of age. From this age onwards, humans realize that an agent's internal mental states may differ considerably from the actual state of the world or from one's own mental states. By contrast, in the case of an omniscient agent, mental states 
always correspond to the state of the world. If such an agent believes that $p$, then $p$ is simply the case. Consequently, such mental states are easier to represent than mental states of normal agents, because the latter require that one keep both the state of the world and their mental states in mind. In line with this, cross-cultural psychological studies (e.g., Knight et al. 2004) indicate that an understanding of God's mental states arises earlier in development than that of other agents, typically around the age of three. Toddlers start out attributing omniscience to all agents (e.g., their parents), but later in cognitive development they restrict this to God. Children come to realize from their experience that their parents do not know everything, but as they constantly receive testimony that God is omniscient, they have no reason to scale down that expectation. From a cognitive point of view, the inference to an omniscient creator of the universe is not an unlikely step.

How do early-developed intuitions about causality and agency precisely figure as reasons for holding the cosmological argument? There are two ways in which reasons for developing or endorsing the cosmological argument can be articulated. The first, which an agent can do retrospectively, corresponds most to the commonsense notion of reason. It consists of a reconstruction of an agent's subconscious states when she was formulating the argument. Such states could include, for example, habitual modes of making inferences that cohere with the agent's worldview. A second conception is quite different. Not only the agent, but also others, such as friends, family or other people who know the agent well, can try to make those reasons explicit. Such persons have what Pollard (2005, 80) terms 'second person authority' about our reasons. Experts on the human mind (such as developmental psychologists and cognitive neuroscientists), if they are worth their salt, also have second person authority about our reasons: they can formulate informed ideas about how the mind draws certain conclusions and what cognitive stable intuitions may underlie these.

As we outlined earlier, many developmental psychologists (e.g., Carey \& Spelke, 1996) subscribe to the view that early-developing principles of human reasoning (in their terminology, core knowledge) do not get fundamentally revised over time. Rather, they get enriched and sophisticated through experience and education. Obviously, the causal inferences that scholars trained in philosophy and theology formulate are far beyond the rudimentary causal understanding of young children. Yet, if developmental psychologists who articulated the notion of core knowledge turn out to be correct, there are good reasons to assume that philosophers and theologians are still guided by these early developed, cognitively stable intuitions about causality and agency. These intuitions can be explicitly articulated, addressed and challenged in 
philosophical and theological discourse, as for example, in the discussion between Grünbaum (2000) and Craig (2001) on intuitions that underlie the cosmological argument. The fact that philosophers can do this is compatible with our claim that these intuitions have their origin in normal cognitive processes. As Williamson remarks: "Neither their content [of intuitions in philosophy] nor the cognitive basis on which they are made need be distinctively philosophical" $(2007,3)$. Instead, one should not be surprised that reasoning skills that are used in philosophy and theology are what Williamson terms:

cases of general cognitive capacities used in ordinary life, perhaps trained, developed, and systematically applied in various special ways, just as the cognitive capacities that we use in mathematics and natural science are rooted in more primitive cognitive capacities to perceive, imagine, correlate, reason, discuss (2007, 136).

In the case of causal cognition, we have indicated continuities between commonsense causal reasoning and causal inferences that underlie the cosmological argument, such as the inference of causes to unique events, the preference for a necessary cause, and the favored postulation of an agent as cause.

\section{Evolutionary Debunking Arguments}

Given that intuitions about causality and agency play an important role in the formulation and acceptance of the cosmological argument, what are the implications for its cogency? In what follows, we consider implications for the justification of the cosmological argument from externalist and internalist perspectives. According to one externalist view, cognitive accounts of religion cast doubt on the validity of religious beliefs (e.g., Dennett 2006). This can be placed within the broader context of "evolutionary debunking arguments" (a term coined by Kahane, 2011): since evolution is not a truth tracking, but a fitness-enhancing process, beliefs that have an origin in the evolved structure of our minds are unreliable. This casts doubt on their epistemic justification. Evolution can lead our cognitive faculties to produce false beliefs or suboptimal decisions. In some cases, cognitive processes might deviate from the truth due to a fitness trade-off between accuracy and efficiency: given that animals have limited time and resources, they will sometimes be better off with fast heuristics than with faculties that are slow and always truth-preserving. For example, there is little point in deliberating the most optimal escape route when faced with a hungry predator. In this view, the propensity to attribute causes may be a useful heuristic rather than an accurate reflection of the structure of the world. Sometimes natural selection will promote cognitive faculties 
that err on the side of safety, especially when one has little information, and when the costs of false positives and false negatives are asymmetric. This asymmetry can lead to the evolution of cognitive predispositions that are triggered easily and give rise to many false positives (Guthrie 1993, Stephens 2001). Arguably this is the case for causality and agency detection. Suppose one hears a noise in the night: assuming that the sound is uncaused when in fact it is caused by an intruder, a false negative is potentially a lot more costly (e.g., being murdered in one's bed) than the cost of a false positive, where one investigates in vain and goes back to sleep.

Other authors maintain that our cognitive faculties work reliably under normal circumstances, but not in situations that are remote from the conditions in which they evolved. Accordingly, the evolutionary origin of causal intuitions provides prima facie evidence against the soundness of the cosmological argument, as it applies causal intuitions to a domain that is not ecologically relevant, namely the universe as a whole rather than states of affairs in our everyday life. Stewart-Williams presents the following evolutionary debunking argument:

We should be extremely cautious about accepting that there must be a causal answer to the question of why there is something rather than nothing. One popular answer to this question is to posit God as First Cause. However, we cannot rely on the intuition that there must be an ultimate cause for the universe as a whole. [...] [This] weakens the First Cause argument for the existence of $\operatorname{God}(2005,801)$.

One problem with this line of reasoning is that we simply do not know whether the attribution of a cause for the existence of the universe is actually off-track. Our causal intuitions are often correct (e.g., the sound at night was caused by the cat). There is no a priori reason to assume that they are off the mark when we apply them to the universe as a whole. Arguing that causal cognition does not work in the case of theism simply begs the question.

Should we doubt either the causal principle itself or its applications outside of the domain of common sense reasoning, we would be faced with the unwelcome consequence that causal cognition is unreliable in the domain of science. After all, science has only developed in the last few hundred years, and therefore does not constitute an ecologically relevant domain for our cognitive faculties. Moreover, holding erroneous scientific beliefs (such as that the Earth is some 6,000 years old) does not seem to have a negative impact on human fitness (fundamentalist families tend to be large). Yet causality is an important metatheoretical assumption of science that cannot be proven. It therefore seems that rejecting the causal principle outside of the domain of commonsense reasoning comes at a high price. The soundness of our intuitions in the cosmological argument remains an open question. 


\section{Properly Basic Causal Intuitions?}

A second externalist line of reasoning might argue that our causal intuitions are warranted, because they are properly basic. They are basic because one does not need to ground them in arguments or in evidence from other propositions, and they are properly so in virtue of their truth (or probable truth) being obvious and transparent to the subject. Examples of basic beliefs include belief in an external world and in the existence of other minds. According to Reformed epistemologists like Plantinga (2000), some religious beliefs are properly basic; they derive their warrant from the view that God designed the human mind in such a way that it spontaneously forms these beliefs under a wide variety of circumstances. According to this model, the human mind has a sensus divinitatis, an innate cognitive disposition that produces belief in God under a diverse range of conditions.

The cognitive science of religion has remarkably converged on this basicality of religious beliefs, by indicating that they arise naturally and spontaneously without deliberation or instruction (Clark \& Barrett 2010). In the case of causal intuitions, the evidence suggests that humans are cognitively predisposed to think that every contingent object or event must have a cause. Thus, the assumption that God is the cause of the universe seems plausible. God is perceived as a good explanation for the universe, because human intuitive notions of causality favor personal over impersonal causes. On this view, our causal intuitions do not figure as premises in an argument, but rather, they are spontaneously elicited when we consider the universe and its origin. Although strictly speaking in this case, there is a brief inference, the inference would be very quick, obvious and elementary. Reformed epistemologists such as Alvin Plantinga (cf. 2000) include such beliefs in the category of basic beliefs.

It may seem surprising to include causal theistic intuitions in the category of basic beliefs. After all, traditionally, Reformed epistemologists have drawn a sharp distinction between belief in God as properly basic and belief in God as a consequence of argumentation, i.e., natural theology. Some have argued that the idea of properly basic theistic belief motivates opposition to natural theology (e.g., Plantinga 1983, 63-73). However, such a sharp dichotomy may be overstated. Sudduth's (2009) historical examination indicates that natural theology was widely endorsed within the Reformed tradition up until the latter 19th century. In some cases, basic belief and natural theology are more part of a continuum than direct opposites. For example, considerations about the complexity or fine-tuning of the universe might start out as an unreflective sense of wonderment, but it can form the starting point of 
explicit arguments from design. Similarly, a sense of fascination about the world's existence can form the beginning of a more formalized cosmological argument.

The warrant of our causal intuitions depends on the externalist position one adopts, namely a Reformed epistemological account of causal intuitions or an evolutionary explanation. In both cases, a belief is only warranted if it is produced by cognitive processes that successfully aim at the truth. As Plantinga $(2000,187)$ argues, a false belief can have warrant, provided that the cognitive processes that produce it are typically truth-preserving. This can happen, for example, when the cognitive faculty that produces the belief is working at the limit of its capacity. Applying this to an evolutionary point of view, this would mean that in the case of cosmology human causal intuitions would be working at the limit of their capacity, since natural selection has honed these intuitions in such a way that we can successfully interact with our everyday environment. Now suppose that theism is false, then a theist who forms the spontaneous belief that the universe requires a causal origin, and that this origin is God, would be warranted, even though in this case he would be wrong. By contrast, according to the Reformed epistemological model, if theistic belief is false, then there is no sensus divinitatis and therefore, the externalist justification of theistic belief (by virtue of a creator who has instilled belief in God) disappears. A surprising consequence of Plantinga's position is that an evolutionary perspective allows for belief in God that is both false and warranted, whereas Reformed epistemology does not. If one does not take theism as a given, the basicality of causal intuitions does not help one decide whether the cosmological argument is true, or whether these intuitions are perhaps false but warranted.

\section{Epistemic Satisfaction}

The cognitive science literature on causal cognition can also be incorporated in an internalist position where cosmological arguments fulfill an epistemic need. Religious arguments rarely persuade: people seldom accept or reject religious beliefs on the basis of arguments. This is true for both theist and nontheist religious arguments, for example, the claim that natural evil (such as earthquakes or diseases) is incompatible with a benevolent and omnipotent God, typically does not convince theists to abandon their belief in such a being. Faust (2008) argues that religious arguments do not persuade because they beg the doxastic question: the probability one assigns to at least one of the premises depends on whether or not one accepts the argument's conclusion. 
Such arguments are not strictly speaking circular, since they do not state their conclusion in the premises, but the fact that they require belief in the conclusion to be persuasive makes them question-begging in a doxastic sense.

Take the key premises of the Kalām cosmological argument (whatever begins to exist has a cause of its existence; the world began to exist). It is no coincidence that theists find them more likely than nontheists. Proponents (e.g., Craig, 2001) often appeal to the Big Bang theory as scientific support for these premises. However, the Big Bang theory describes only the expansion and cooling of the universe, but says nothing of its origin. Within the standard interpretation of this theory, the universe inflated from a tiny speck to the size it is today, and will continue to do so. Given that matter cannot be infinitely packed, we cannot trace the universe back to an infinitely packed state (Faber, 2006). This seems to warrant the following inference: the universe is only finitely old, and started out as a singularity (a very densely packed state). According to this picture, it does not make sense to talk about time and space prior to 14-15 billion years ago, since time and space began when the universe began to inflate. This corresponds to the second premise of the Kalām cosmological argument.

Nevertheless, other interpretations could be given. For example, one could argue that in the case of a singularity, every moment of the Big Bang model $(t>0)$ is preceded by earlier moments, so that there is no moment at which the universe began to exist $(t=0)$ (Pitts, 2008). Such interpretations of the Big Bang theory assume a B-theory of time, according to which events are ordered by tenseless relations, and all events are on an ontological par. In this B-theoretical interpretation, it is possible to say that the universe, while it is finitely old, never came into existence. Unsurprisingly, proponents of the cosmological argument (e.g., Craig, 1998) favor an A-theory of time, where the only temporal items that exist are those that presently exist. This indicates that scientific evidence itself is not decisive for the cosmological argument, but rather the way in which it is interpreted, and these interpretations depend on the prior probability one accords to the existence of God.

Nontheistic critics do not accept cosmological arguments because they accord an initially low probability to theism. As Mackie (1982, 100) wrote: 'the hypothesis of divine creation is very unlikely.' Materialists may find the existence of the universe as a necessary fact appealing, since their worldview favors the metaphysical primacy of the material world. To them, indeed, there is no reason why the universe, as Hume (1779, IX, 164-165) put it, could not be the necessary self-existent being. Theists, on the other hand, accord a high prior probability to the existence of God, and find God an epistemically satisfying explanation. To quote Swinburne: 
the choice is between the universe as stopping point and God as stopping point. In the latter case, God's existence and intention over all the universe's history will provide not merely a full explanation but a complete and ultimate explanation of the existence of the universe $(2004,147)$.

If the cosmological argument does not persuade non-theists, what does it accomplish? By presenting a justification for beliefs that one already holds on the basis of faith or perhaps weak evidence, religious arguments are primarily aimed at those who already believe (Faust, 2008). Cosmological arguments may fulfill distinct cognitive needs by providing a sense of epistemic satisfaction. Starting from premises that humans find intuitively appealing, such as the causal principle and ideas about agency, such arguments can show that theism is a satisfying explanation for questions like 'why is there something, rather than nothing?' The sense of epistemic satisfaction that arguments from natural theology can provide is perhaps more important than their value as proofs, in other words, while such arguments do not afford a formal proof for the existence of God, they are nevertheless rationally compelling to creatures like us, given our natural cognitive faculties. Kant (1781[2005]) made a similar claim about natural theology and its link with the structure of the human mind: these intuitions may be misleading because they are subject to the limitations of the human cognitive apparatus, but they are also unavoidable and irresistibly convincing (A624/B652) given the structure of human reasoning (see Byrne, 2007, chapters 2 and 3, for a critical analysis). As we have discussed earlier (De Cruz \& De Smedt, 2010), the persuasive force of the argument from design might likewise be a consequence of its concurrence with human cognitive predispositions, in particular a pervasive tendency to see purpose and design in nature which emerges universally in young children and remains stable throughout adult life. However, while Kant assumed that such causal and teleological intuitions are inherently misleading, this remains an open question, as we have pointed out in section III. From an internalist perspective, it is therefore possible to treat the intuitions that underlie the cosmological argument as starting points in explanatory strategies that make theism a more coherent position. The ability to move within the space of reasons, to formulate cogent arguments (including religious arguments) critically depends on such core intuitions that are a stable part of human cognition. These intuitions (in particular, those about causality and agency) make it possible to develop and evaluate cosmological arguments. If humans were unable to posit unobservable causes (as our closest nonhuman relatives seem to be), cosmological arguments would simply be unintelligible.

Experimental evidence from cognitive psychology (Koslowski et al. 2008) reveals an intricate interplay between explanation and evidence: subjects treat 
information as evidence if they can incorporate it in a causal framework. They are more likely to treat background information as relevant to an explanation for an event when the explanation can incorporate both the event and the background information into a single causal account, which makes the overarching explanation increasingly convincing. Merely saying that God created the universe is not as epistemically satisfying as providing a coherent, explanatory account of why we should believe that he did. The cosmological argument can make theism more plausible by its ability to incorporate background information (e.g., the Big Bang theory) and universal human intuitions about causality and agency into a convincing overarching explanatory account (God as the best explanation for the beginning of the universe). By its ability to unify scientific knowledge, intuitions about causality and agency, and theism, the cosmological argument contributes to a more coherent worldview in theists, for whom the existence of the universe is a fact in need of explanation. As Craig put it: 'Even if the uncaused origin of the universe were natural relative to the Standard Big Bang model, that would not imply that the origin of the universe does not cry out for explanation' $(2001,379)$.

\section{References}

Ahn, W., Kalish, C.W., Medin, D.L., \& Gelman, S.A. (1995). The role of covariation versus mechanism information in causal attribution. Cognition, 59, 299-352.

Bering, J.M., Hernández Blasi, C., \& Bjorklund, D.F. (2005). The development of 'afterlife' beliefs in religiously and secularly schooled children. British Journal of Developmental Psychology, 23, 587-607.

Blackburn, S. (2001). Normativity à la mode. Journal of Ethics, 5, 139-153.

Bräuer, J., Kaminski, J., Riedel, J., Call, J., \& Tomasello, M. (2006). Making inferences about the location of hidden food: Social dog, causal ape. Journal of Comparative Psychology, 120, 38-47.

Byrne, P. (2007). Kant on God. Aldershot: Ashgate.

Call, J. \& Tomasello, M. (1999). A nonverbal false belief task: The performance of children and great apes. Child Development, 70, 381-395.

Callaghan, T., Rochat, P., Lillard, A., Claux, M.L., Odden, H., Itakura, S., Tapanya, S., \& Singh, S. (2005). Synchrony in the onset of mental-state reasoning: Evidence from five cultures. Psychological Science, 16, 378-384.

Carey, S. \& Spelke, E.S. (1996). Science and core knowledge. Philosophy of Science, 63, 515533.

Clark, K.J. \& Barrett, J.L. (2010). Reformed epistemology and the cognitive science of religion. Faith \& Philosophy, 27, 174-189.

Craig, W.L. (1998). Theism and the origin of the universe. Erkenntnis, 48, 47-57.

- (2001). Prof. Grünbaum on the 'Normalcy of Nothingness' in the Leibnizian and Kalam cosmological arguments. British Journal for the Philosophy of Science, 52, 371-386.

- (2003). The cosmological argument. In P. Copan \& P.K. Moser (Eds.), The rationality of theism (pp. 112-131). London \& New York: Routledge. 
Davidson, D. (1963). Actions, reasons, and causes. Journal of Philosophy, 60, 685-700.

De Cruz, H., \& De Smedt, J. (2010). Paley's iPod. The cognitive basis of the design argument within natural theology. Zygon: Journal of Religion and Science, 45, 665-684.

Dennett, D.C. (2006). Breaking the spell: Religion as a natural phenomenon. New York: Viking.

Faber, S.M. (2006). The Big Bang as scientific fact. Annals of the New York Academy of Sciences, $950,39-53$.

Faust, J. (2008). Can religious arguments persuade? International Journal for the Philosophy of Religion, 63, 71-86.

Gelman, S.A. \& Gottfried, G.M. (1996). Children's causal explanations of animate and inanimate motion. Child Development, 67, 1970-1982.

Gelman, S.A., \& Wellman, H.M. (1991). Insides and essences: Early understandings of the nonobvious. Cognition, 38, 213-244.

Grünbaum, A. (2000). A new critique on theological interpretations of physical cosmology. British Journal for the Philosophy of Science, 51, 1-43.

Guthrie, S.E. (1993). Faces in the clouds. A new theory of religion. New York \& Oxford: Oxford University Press.

Hassin, R.R., Bargh, J.A., \& Uleman, J.S. (2002). Spontaneous causal inferences. Journal of Experimental Social Psychology, 38, 515-522.

Hume, D. (1748). Philosophical essays concerning human understanding. London: Millar. (1779). Dialogues concerning natural religion. London: Hafner.

Hurley, S. (2003). Animal action in the space of reasons. Mind \& Language, 18, 231-256.

Kahane, G. (2011). Evolutionary debunking arguments. Noûs, 45, 103-125.

Kant, I. (1781 [2005]). Critique of pure reason (Guyer, P. \& Wood, A., Eds.). Cambridge: Cambridge University Press.

Kelemen, D. (2004). Are children "intuitive theists"? Reasoning about purpose and design in nature. Psychological Science, 15, 295-301.

Knight, N., Sousa, P., Barrett, J.L., \& Atran, S. (2004). Children's attributions of beliefs to humans and God: Cross-cultural evidence. Cognitive Science, 28, 117-126.

Koons, R.C. (1997). A new look at the cosmological argument. American Philosophical Quarterly, 34, 193-211.

Koslowski, B., Marasia, J., Chelenza, M., \& Dublin, R. (2008). Information becomes evidence when an explanation can incorporate it into a causal framework. Cognitive Development, 23, 472-487.

Mackie, J.L. (1982). The miracle of theism. Arguments for and against the existence of God. Oxford: Clarendon Press.

Martin, A., \& Weisberg, J. (2003). Neural foundations for understanding social and mechanical concepts. Cognitive Neuropsychology, 20, 575-587.

McDowell, J. (1996). Mind and world. Cambridge, MA: Harvard University Press.

Metz, K.E. (1998). Emergent understanding and attribution of randomness: Comparative analysis of the reasoning of primary grade children and undergraduates. Cognition and Instruction, 16, 285-365.

Newman, G.E., Keil, F.C., Kuhlmeier, V.A., \& Wynn, K. (2010). Early understandings of the link between agents and order. Proceedings of the National Academy of Sciences USA, 107, $17140-17145$.

Pitts, J.B. (2008). Why the Big Bang singularity does not help the kaläm cosmological argument for theism. British Journal for the Philosophy of Science, 59, 675-708.

Plantinga, A. (1983). Reason and belief in God. In: A. Plantinga \& N. Wolterstorff (Eds.), Faith and rationality: Reason and belief in God (pp. 16-93). Notre Dame, IN: University of Notre Dame Press.

-. (2000). Warranted Christian belief. New York: Oxford University Press. 
Pollard, B. (2005). Naturalizing the space of reasons. International Journal of Philosophical Studies, 13, 69-82.

Povinelli, D., \& Dunphy-Lelii, S. (2001). Do chimpanzees seek explanations? Preliminary comparative investigations. Canadian Journal of Experimental Psychology, 55, 185-193.

Rasmussen, J. (2010). From states of affairs to a necessary being. Philosophical Studies, 148, 183200.

Rowe, W. (2005). Cosmological arguments. In: W.E. Mann (Ed.), The Blackwell guide to the philosophy of religion (pp. 103-116). Oxford: Blackwell.

Saxe, R., Tenenbaum, J., \& Carey, S (2005). Secret agents: Inferences about hidden causes by 10- and 12-month-old infants. Psychological Science, 16, 995-1001.

Scholl, B.J. \& Tremoulet, P. (2003) Perceptual causality and animacy. Trends in Cognitive Sciences, 4, 299-309.

Schulz, L. \& Sommerville, J. (2006). God does not play dice: Causal determinism and preschoolers' causal inferences. Child Development, 77, 427-442.

Sellars, W. (1956). Empiricism and the philosophy of mind. In: H. Feigl and M. Scriven (Eds.), Minnesota studies in the philosophy of science, foundations of science and the concepts of psychology and psychoanalysis (pp. 253-329). Minneapolis: University of Minnesota Press.

Shultz, T.R. (1982a). Rules of causal attribution. Monographs for the Society for Research in Child Development, 47, 1-51.

. (1982b). Causal reasoning in the social and nonsocial realms. Canadian Journal of Behavioral Science, 14, 307-322.

Spelke, E.S. \& Kinzler, K.D. (2007). Core knowledge. Developmental Science, 10, 89-96.

Spelke, E.S., Phillips, A., \& Woodward, A.L. (1995). Infants' knowledge of object motion and human action. In D. Sperber, D. Premack, \& A.J. Premack (Eds.), Causal cognition. A multidisciplinary debate (pp. 44-78). Oxford: Clarendon Press.

Stephens, C.L. (2001). When is it selectively advantageous to have true beliefs? Sandwiching the better safe than sorry argument. Philosophical Studies, 105, 161-189.

Stewart-Williams, S. (2005). Innate ideas as a naturalistic source of metaphysical knowledge. Biology \& Philosophy, 20, 791-814.

Sudduth, M. (2009). The Reformed objection to natural theology. Farnham: Ashgate.

Swinburne, R. (2004). The existence of God. Oxford: Clarendon Press.

Vonk, J. \& Povinelli, D.J. (2006). Similarity and difference in the conceptual systems of primates: The unobservability hypothesis. In E. Wasserman \& T. Zentall (Eds.), Comparative cognition: Experimental explorations of animal intelligence (pp. 363-387). Oxford: Oxford University Press.

Wegner, D.M. (2003). The mind's self-portrait. Annals of the New York Academy of Sciences, $1001,212-225$.

Williamson, T. (2007). The philosophy of philosophy. Oxford: Blackwell. 